\title{
Subarachnoid hemorrhage: mortality in a South American Country
}

Hemorragia subaracnoidea: mortalidade em um país sul-americano

Jefferson Gomes Fernandes

Neurologist, Superintendent of Education and Sciences, Hospita Alemão Oswaldo Cruz, São Paulo SP, Brazil.

\section{Correspondence:}

Jefferson Gomes Fernandes Instituto de Educação e Ciências em Saúde, Hospital Alemão

Oswaldo Cruz

Rua João Julião 331

CEP 01323-903 São Paulo SP - Brasil.

E-mail: jeffersonfernandes@haoc. com.br

Conflict of interest:

There is no conflict of interest to declare.

Received 04 October 2013

Accepted 11 October 2013
$\mathrm{N}$

on-traumatic subarachnoid hemorrhage (SAH) usually caused by aneurysm rupture is a potentially devastating condition, feared both by patients and physicians. It is estimated that death from SAH occurs before hospital admission in $12 \%$ to $15 \%$ of cases $^{1}$. The epidemiology of SAH shows some particularities which professionals involved with health policies and the care of people with this disorder should be aware of. Age, gender, income, race and ethnicity have a significant impact on SAH presentation.

There is a wide variation in the annual incidence of SAH in different regions of the world, from 2 cases per 100000 population in China to 22.5 cases per 100000 in Finland as shown by the WHO MONICA Stroke Study ${ }^{2}$. In South and Central America the SAH incidence is reported to be 4.2 per 100000 person-years ${ }^{3}$ with studies from Chile and Barbados indicating incidences of 6.2 per 100000 per year (3.0-9.3) and 3.0 per 100000 per year (1.0-5.0), respectively ${ }^{4}$.

$\mathrm{SAH}$ incidence increases with age, with an average age of onset in adults of $\geq 50$ years, being 1.24 times higher in women than in $\operatorname{men}^{3,5}$. In a Brazilian study the age-adjusted incidence for SAH was higher among females and increased progressively with age ${ }^{6}$. Mortality data obtained from the city of Sao Paulo Health Statistic System (PRO-AIM) identified SAH as a much more frequent cause of death among women when compared to men ${ }^{7}$. Race and ethnicity are relevant factors in SAH with Blacks and Hispanics having a higher incidence than white Americans ${ }^{8}$. A study reviewing data on approximately one billion hospitalizations in the United States over a 30-year study period (1979-2008) identified 612500 cases of SAH, which was more common in women and non-white persons9.

The impact of income on SAH rates was reported in a recent systematic review of population-based studies, where the incidence of SAH ranged from 2 to 16 per 100 000, with a pooled age-adjusted incidence rate in low to middle-income countries almost double that found in high income countries ${ }^{5}$. Another study found a significant income-mortality association for SAH among US patients, which was absent among Canadian patients ${ }^{10}$. The prevalence of intracranial aneurysms in the general population appears to be $2-5 \%$ and the frequency of unruptured aneurysms in angiographic and prospective autopsy series is approximately $3-4 \%^{11}$. In population-based studies of Latin American and the Caribbean 2-5\% of all strokes were subarachnoid hemorrhage ${ }^{4}$. In a study of 2418 consecutive patients from 19 hospitals in the city of Fortaleza, Brazil, the frequency of admissions of subarachnoid hemorrhage patients was $6.0 \%{ }^{12}$.

The case fatality of SAH seems to remain high worldwide. However, mortality rates appear to have declined in industrialized nations over the past 25 years $^{13}$. Mortality rates vary widely across published epidemiological studies, ranging from $8 \%$ to $67 \%$ with a median mortality rate in the United States of $32 \%$ versus $43 \%$ in Europe and $27 \%$ in Japan14. In this issue of Arquivos de Neuropsiquiatria, Alcalá-Cerra et al.15 publish an important study which assessed the trends in mortality due to non-traumatic subarachnoid hemorrhage from 1999 to 2008 in Colombia. The study was based on the analysis of all deaths in the country over this period, and data was obtained from the Colombian national registry of deaths. During the 10-year study period, 1,893,635 deaths were recorded with a total of 17,272 deaths registered as SAH-related, ranging from 3.9 to 4.4 deaths per 100,000 people. The information presented by this study helps to understand the impact of such disease on the health system not only in 
Colombia, but also in developing countries with similar population demographics.

As for other disorders, the assessment of stroke rates, including mortality, is best achieved with standardized population-based studies ${ }^{16}$. The term population-based is traditionally used to describe a study that involves a defined "general population" as opposed to hospital-based or database of death certificate studies. Analyses limited to hospitalbased stroke registers or incomplete mortality data may distort results because of non-representative study populations or underestimation of cases. Differences in study methodologies may account for different rates observed in stroke descriptive epidemiologic studies. Variations in stroke case ascertainment and evaluation, classification, definition of event rates, data presentation and statistical analysis (e.g.: use of age-adjusted data and of confidence intervals) make direct comparisons difficult among epidemiological studies. Standard definitions, procedures, methods and data presentation are important to allow more reliable comparisons in much needed stroke epidemiological studies.

\section{References}

1. Schievink WI, Wijdicks EF, Parisi JE, Piepgras DG, Whisnant JP. Sudden death from aneurysmal subarachnoid hemorrhage. Neurology 1995;45:871-874.

2. Ingall T, Asplund K, Mahonen M, Bonita R. A multinational comparison of subarachnoid hemorrhage epidemiology in the WHO MONICA stroke study. Stroke 2000;31:1054-1061.

3. de Rooij NK, Linn FH, van der Plas JA, Algra A, Rinkel GJ. Incidence of subarachnoid haemorrhage: a systematic review with emphasis on region, age, gender and time trends. J Neurol Neurosurg Psychiatry 2007;78:1365-1372.

4. Lavados PM, Hennis AJM, Fernandes JG, et al. Stroke epidemiology, prevention, and management strategies at a regional level: Latin America and the Caribbean. Lancet Neurol 2007;6:362-372.

5. Feigin VL, Lawes CM, Bennett DA, Barker-Collo SL, Parag V. Worldwide stroke incidence and early case fatality reported in 56 populationbased studies: a systematic review. Lancet Neurol 2009; : 55-369.

6. Cabral NL, Gonçalves ARR, Longo AL, et al. Incidence of stroke subtypes, prognosis and prevalence of risk factors in Joinville, Brazil: a 2 year community based study. J Neurol Neurosurg Psychiatry 2009:80;755-761.

7. Lotufo PA, Bensenor IM. Stroke Mortality in São Paulo (1997-2003). A description using the Tenth Revision of the International Classification of Diseases Arq Neuropsiquiatr 2004;62:1008-1011.

8. Labovitz DL, Halim AX, Brent B, Boden-Albala B, Hauser WA, Sacco RL. Subarachnoid hemorrhage incidence among Whites, Blacks and Caribbean Hispanics: the Northern Manhattan Study. Neuroepidemiology 2006;26:147-150.
9. Rincon F, Rossenwasser RH, Dumont A. The epidemiology of admissions of nontraumatic subarachnoid hemorrhage in the United States. Neurosurgery 2013;73:217-223.

10. Jaja BNR, Saposnik G, Nisenbaum R, et al. Effect of Socioeconomic Status on Inpatient Mortality and Use of Postacute Care After Subarachnoid Hemorrhage. Stroke 2013;44:2842-2847.

11. Rinkel GJ, Djibuti M, Algra A, van Gijn J. Prevalence and risk of rupture of intracranial aneurysms: a systematic review. Stroke 1998;29:251-256.

12. Carvalho JJF, Alves MB, Viana GAA, et al. Stroke epidemiology, patterns of management, and outcomes in Fortaleza, Brazil. A hospital-based multicenter prospective study. Stroke 2011; 42:3341-3346.

13. Stegmayr B, Eriksson M, Asplund K. Declining mortality from subarachnoid hemorrhage: changes in incidence and case fatality from 1985 through 2000. Stroke. 2004; 35: 2059-2063.

14. Nieuwkamp DJ, Setz LE, Algra A, Linn FH, de Rooij NK, Rinkel GJ. Changes in case fatality of aneurysmal subarachnoid haemorrhage over time, according to age, sex, and region: a meta-analysis. Lancet Neurol. 2009; 8: 635-642.

15. Alcalá-Cerra G, Young AMH, Paternina-Caicedo A, Ribas ESC, on behalf of Health Sciences and Neurociences Research Group (CISNEURO). Trends in mortality of non-traumatic subarachnoid hemorrhage in Colombia: a 10-year analysis of a nationwide registry. Arq Neuropsiquiatr 2013;71:841-845.

16. Feigin VL, Carter K. Editorial comment-stroke incidence studies one step closer to the elusive gold standard? Stroke 2004;35:2045-2047. 